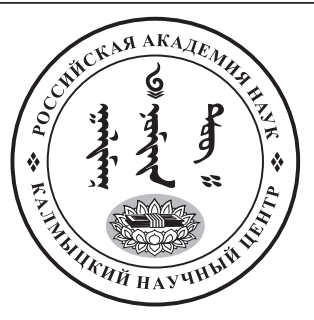

Published in the Russian Federation

Oriental Studies (Previous Name: Bulletin of the Kalmyk Institute

for Humanities of the Russian Academy of Sciences)

Has been issued as a journal since 2008

ISSN: 2619-0990; E-ISSN: 2619-1008

Vol. 13, Is. 1, pp. 55-63, 2020

DOI: $10.22162 / 2619-0990-2020-47-1-55-63$

Journal homepage: https://kigiran.elpub.ru

УДК 396.6

\title{
Положение «дулгуяк-кадай» в традиционной культуре тувинцев (вторая половина XIX - начало XXI в.)
}

\author{
Зоя Юрьевна Доржу', Людмила Александровна Даш² \\ 1 Тувинский государственный университет (д. 36, ул. Ленина, 667000 Кызыл, Российская \\ Федерация) \\ доктор исторических наук, профессор, заведующий кафедрой отечественной истории \\ iD 0000-0002-6409-3248. E-mail: zoyadorzhu@yandex.ru
}

2 Тувинский государственный университет (д. 36, ул. Ленина, 667000 Кызыл, Российская Федерация)

аспирант кафедры отечественной истории

iD 0000-0003-4065-9777. E-mail: mila.dash.88@mail.ru

(C) КалмНЦ РАН, 2020

(С Доржу 3. Ю., Даш Л. А., 2020

\begin{abstract}
Аннотация. В статье поставлена цุель - анализ социовозрастной группы дулгуяк-кадай, что в переводе с тувинского означает 'старая дева', особенностей их положения в традиционном тувинском обществе и в современных условиях. Полевые материалы получены от непосредственных носителей народных традиций, и в этом их ценность. Результаты. Во все времена в Туве была высока ценность брака, главным предназначением женщины-тувинки - херээжен кижи было быть женой и матерью. Поэтому дулгуяк-кадай вызывали жалость и даже пренебрежение по отношению к ним. Эта социовозрастная группа не вписывалась в установившийся порядок тувинского традиционного социума, однако включалась в его жизнь, составляя неотъемлемую его часть, способствуя расшатыванию патриархальных устоев тувинского общества. На основании историко-этнографических данных, собранных авторами в ходе комплексной экспедиции в ряде районов в течение 2018-2019 гг., и других источников выявлены причины безбрачия девушек, показана роль дулгуяк-кадай в жизни отцовской семьи, отношение к ней ее членов и общества в целом. Отмечены некоторые особенности данного явления в современных условиях утраты народных традиций, с влиянием процессов глобализации.

Ключевые слова: тувинцы, женщины, семья, дулгуяк-кадай, старые девы, брачно-семейные отношения, традиционное общество, традиции, обычаи

Для цитирования: Доржу 3. Ю., Даш Л. А. Положение «дулгуяк-кадай» в традиционной культуре тувинцев (вторая половина XIX - начало XXI в.) // Oriental Studies. 2020. Т. 13. № 1. С. 55-63. DOI: 10.22162/2619-0990-2020-47-1-55-63
\end{abstract}


UDC 396.6

\title{
Status of Dulguyak-Qadai in Tuvan Traditional Culture: Mid-19 ${ }^{\text {th }}$ to Early $21^{\text {st }}$ Centuries
}

\author{
Zoya Yu. Dorzhu', Lyudmila A. Dash² \\ ${ }^{1}$ Tuvan State University (36, Lenin St., Kyzyl 667000, Russian Federation) \\ Dr. Sc. (History), Professor, Head of Department of Russian History \\ iD 0000-0002-6409-3248. E-mail: zoyadorzhu@yandex.ru \\ ${ }^{2}$ Tuvan State University (36, Lenin St., Kyzyl 667000, Russian Federation) \\ Postgraduate Student \\ iD 0000-0003-4065-9777. E-mail: mila.dash.88@mail.ru \\ (C) KalmSC RAS, 2020 \\ (C) Dorzhu Z. Yu., Dash L. A., 2020
}

\begin{abstract}
Goals. The article studies the socio-age group of dulguyak-qadai (Tuv. 'old maid'), specific features of their status in traditional and contemporary Tuvan society. The institution of marriage has always been highly valued in Tuva, and central life goal of any Tuvan woman was to become a hereezhen kizhi, i.e. wife and mother. So, the dulguyak-qadai used to be objects of pity or even neglect. Old maids - as well as the very concept of dulguyak - constituted and literally denoted a 'deviation' from the traditional worldview and established Tuvan social structure, though remaining its active integral part which would significantly undermine patriarchal foundations of Tuvan community. Materials. The work analyzes historical, ethnographic data collected during 2018-2019 comprehensive expeditions to a number of districts (and other sources) revealing why women stay unmarried, the latter's roles in their parental families, attitudes of other relatives and those of community members in general. Results. The paper notes some present-day features of the phenomenon in the context of vanishing folk traditions and increasing globalization processes. The field materials obtained from authentic traditional culture bearers are valuable enough, and can be instrumental in compiling curricula and instructional guidelines for ethnic schools, at folk pedagogy advisory meetings, etc.
\end{abstract}

Keywords: Tuvans, women, family, dulguyak-qadai, old maids, marriage and family relations, traditional society, traditions, customs

For citation: Dorzhu Z. Yu., Dash L. A. Status of Dulguyak-Qadai in Tuvan Traditional Culture: Mid- $19^{\text {th }}$ to Early $21^{\text {st }}$ Centuries. Oriental Studies. 2020. Vol. 13. No. 1. Pp. 55-63. (In Russ.). DOI: 10.22162/2619-0990-2020-47-1-55-63

\section{है}

\section{Введение}

Данная статья посвящена исследованию роли и места своеобразной социовозрастной группы дулгуяк-кадай, что в переводе с тувинского означает 'старая дева', их положению в семье и обществе в прошлом и в настоящем, отношение к ним в традиционной тувинской культуре и в современном обществе, где происходят серьезные трансформации общественного уклада и сознания людей.
Женщины, которые к определенному возрасту не достигли статуса жены и матери, вызывали неоднозначную реакцию со стороны окружающих, поэтому важно проследить условия и механизмы включения во все сферы общественной жизни женщин, которые по каким-то причинам не создали семью, не имеют детей. В данной статье рассматривается положение дулгу-

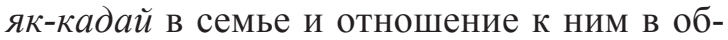
ществе. 
Основой для данной статьи послужили полевые материалы авторов, собранные в ходе комплексной экспедиции в Улуг-Хемский, Чаа-Хольский, Сут-Хольский, Тандинский и Бай-Тайгинский кожууны Республики Тыва в 2018-2019 гг., а также записи конкретных бесед с информантами на данную тему. Время не стоит на месте: меняются люди, условия их жизни, отношение друг к другу и к таким базовым ценностям, как семья, дети. Поэтому появление новых методов исследований, в частности, использование такого метода, как интервью, позволило выявить некоторые интересные факты и подробности, связанные с рассматриваемой проблемой. Сегодня, когда акценты смещаются и становится важен человек - участник этих событий, особую ценность представляют мнения и комментарии людей, которые по долгу службы были связаны с работой среди женщин, либо трудились в сфере образования и культуры.

Наши исследования показали, что в современном обществе отношение к дулгуяк-кадай существенно изменилось, нежели это было в традиционной тувинской культуре. В связи с этим считаем необходимым разделить нашу статью на две части: в одной рассмотрим традиционное общество, а в другой - современное.

Исследования по данной проблеме фрагментарны. Ценные сведения о положении женщины в тувинском обществе встречаются в работах отечественных исследователей дореволюционного периода [Кон 2007; Катанов 2011].

В работах историков и этнографов [Менхен-Хельфен 2007; Яковлев 2007; Кенин-Лопсан 2006; Биче-оол 2018] данная тема изучается с точки зрения быта и культуры традиционного общества.

В последние годы появились работы [Забелина 2010; Доржу 2011; Айыжы 2017], где получили освещение некоторые вопросы, связанные с положением женщины-тувинки в семье и в обществе, взаимоотношениями в современной тувинской семье, проблемами этнокультурного воспитания детей. Однако ни один из названных авторов не рассматривал специально вопрос о положении дулгуяк-кадай в традиционной культуре тувинцев. Это и предопределило выбор темы данной статьи.
Предпринятая авторами попытка восполнить данный пробел вызвала необходимость обратиться к рассмотрению женского пространства в традиционной культуре тувинцев, чтобы выявить, как жили тувинцы раньше и каково было положение женщины в тувинском обществе, разобраться с содержанием понятия дулгуяк-кадай. Это, в свою очередь, вызвало необходимость выяснить, каково значение этого слова: дулгуяк-кадай - это что? Прозвище? Ругательство? Оценка? Как относились к ним? Все это предопределяет актуальность изучения проблем дулгуяк-кадай в связи с изменением сложившихся норм поведения, их жизненных ценностей, влияющих на социальный статус.

\section{Брак: общие замечания}

Брак для тувинцев был обязательным для каждого человека. Старых дев и холостяков не любили и не уважали, их считали плохими людьми. К засидевшейся невесте относились как к неполноценной, имеющей физические и иные недостатки [Доржу 2011: 36]. По свидетельству Ф. Я. Кона, посетившего Туву в составе научной экспедиции, «тувинцы считали, что у девушек, не имевших до 20 лет половых сношений с мужчиной, в матке появляется боль, которая влекла за собой смерть» [Кон 2007: 380].

У современных тувинцев «брачный возраст» отличается, чем это было в более ранние периоды: девушек выдавали замуж в возрасте 16-18 лет, а юноши могли жениться с 18-20 лет и позднее. Важно было, чтобы «жених» и «невеста» были физически крепкими, работящими, почтительными к старшим [Айыжы 2017: 62].

Традиционно придавая большую значимость браку, тувинцы пытались сосватать своих детей чуть ли не в младенчестве. Брак сватовством был очень распространен. Сватали как малолетних детей, так и достигших половой зрелости. Невеста могла быть моложе или старше жениха, но разница должна составлять не более 2-3 лет. Жених же мог быть старше невесты на 10-12 лет, но не младше. Старались, чтобы возраст вступающих в брак был одинаков, но главным был год рождения жениха и невесты.

За советом обращались к шаманам и гадателям по бараньей лопатке с просьбой определить и установить дату свадьбы, даже день и час, когда девушке уезжать из 
аала родителей. После принятия буддизма дату свадьбы устанавливали ламы, которые знали календарь, основанный на двенадцатилетнем животном цикле, и могли определить, подходят ли жених и невеста друг другу по году рождения [Кенин-Лопсан 2006: 27]. Принципиальным было, чтобы животное, в год которого родился жених, физически был сильнее животного, в год которого родилась девушка.

Отношение тувинцев к дулгуяк-кадай

Всякий, кто не вступил в брак, подвергался осуждению и считался ущербным. Существовало мнение, что женщина осталась без мужа, без семьи не столько из-за своей внешности, сколько из-за сварливого характера и неуживчивости. Дулгуяк-кадай - это было не только ненормальным с точки зрения традиционного тувинского общества, противоречащим естественной природе женщины быть женой и матерью, но и оскорблением. Наш информант, 79-летняя Я. Д. Суван, сообщает, что если в той или иной семье есть дулгуяк-кадай, об этом знали во всей округе, и даже в разговоре подчеркивалось, что это тот род, та семья, в которой есть дулгуяк-кадай [ПМА: Суван 2018]. Тувинцы старались не допускать, чтобы женщина была незамужем. Бывало, что девушка выходила замуж за пожилого человека или за вдовца, хотя такие браки не одобрялись.

В традиционном тувинском обществе у семьи, не имевшей детей, также был низкий социальный статус. Женщина, не имеющая детей, не могла быть повитухой, не участвовала в свадебном обряде расплетания косы невесты и в церемонии сшивания овчин для одеяла с просьбой о счастье молодым, не могла укладывать в колыбель новорожденного, так как могла навлечь беду на молодую семью. Бездетная женщина не пользовалась уважением ни в семье, ни в обществе, ее обычно ждала одинокая жизнь или необходимость растить чужих детей [Забелина 2010: 16]. Бездетность считалась признаком ущербности, ибо периодическое рождение детей, пополнение семьи, рода и, через это, участие в продлении времени считалось основной функцией женщины.

Девушка чуть старше 20 лет считалась уже засидевшейся, о ней говорили как о неполноценной, имеющей физические или умственные недостатки [Доржу 2011: 35].
В «Очерках Урянхайской земли» Н. Ф. Катанов пишет, что русалка (албыс) была прежде девицею, не вышедшею замуж. Она живет только в каменистых и песчаных местах, мужчинам делает пакости [Катанов 2011: 78]. Аналогичный пример описал О. Менхен-Хельфен в книге «Путешествие в азиатскую Туву» «Албыс - это черт, вселяющийся в девушек. Албысами становятся те, кто отказывается выходить замуж» [Менхен-Хельфен 2007: 301]

Исследователь тувинского фольклора Г. Н. Курбатский отмечал, что старых дев - дулгуяк-кадай и старых холостяков - дулгуяк ашак не любили (эргекке ораам четпес 'не стоящий даже нитки, которую нельзя обернуть вокруг большого пальца'), их дальше порога не пускали, сажали на самое плохое место, кормили объедками. Относились к ним с презрением: «как косуля без лежбища, как рыба без заводи» [Курбатский 2001: 194].

По сведениям старшего поколения, в традиционной религии тувинцев - шаманизме к дулгуяк-кадай относились снисходительно, они могли быть шаманами. По данным переписи населения 1931 г., из 725 шаманов 314 были женщины. В особых случаях дулгуяк-кадай могли стать и буддийскими священнослужителями. Это отмечал и Ф. Я. Кон: « ... ламы бреют всю голову. Это делают и женщины, давшие во время болезни обет сделаться ламами, так называемые „хуурак-иуваганчыл“ [Кон 2007: 389]. По сведениям наших информантов, большинство хуурак-шуваганчы состояли из дулгуяк-кадай.

Рассмотрим это в сравнении с тувинцами, проживающими в Китае и Монголии. У китайских тувинцев безбрачие также осуждалось. Они не допускались к совершению некоторых обрядов. В частности, их не брали в качестве сватов, считая, что они могут плохо повлиять на ход сватовства. Девушек старше 30 лет считали засидевшимися, старались предпринять меры, чтобы выдать их замуж. Специально устраивали встречи великовозрастных мужчины и женщины, чтобы познакомить их. В народе это известно как чоокшуладыр 'сблизить' или чугаалаштыpыlыр 'разговорить'. Как показали исследования, такая практика была небезуспешной, в результате таких знакомств обычно создавались семьи [Юша 2018: 210-211]. 
Уместно привести и такой пример, который поведал наш информант - 72-летняя М. Д. Шойдак. Так, если девушка долго не могла выйти замуж ей в подарок преподносили туткууш 'прихватки' для ведения домашнего хозяйства, этот предмет домашнего обихода тувинцев преподносила обязательно замужняя женщина, имеющая детей, семейное благополучие и достаток. Tymкууш - парный предмет и преподношение его незамужней девушке означало то, что ее в ближайшее время придут сватать или она выйдет замуж [ПМА: Шойдак 2019].

Таким же пренебрежительным было отношение к нерожавшей женщине у тувинцев Баян-Ульгийского аймака Монголии, Об этом пишет исследователь Е. В. Айыжы в статье «Формы семьи и брака тувинцев России, Монголии и Китая». Их называли уруг үндүрбээн кижи (досл.: 'человек, не «выпустивший», т. е. не родивший ребенка'). Таких женщин остерегались, боялись их проклятий, так как они не могут прочувствовать чужую боль. Старую деву называли өөнге кырып калган уруг 'женщина, состарившаяся в юрте', или эр-даа албас, эрлик-даа албас 'ни парень не берет, ни черт не берет'. При совершении важных жизненных обрядов (имянаречение или свадебный) таких людей старались не приглашать. Старые девы, как и холостяки, не могли иметь своего жилища, да и положение их в семье было неопределенным. В юрте они не могли сидеть на почетном месте, им могли даже отказать в ночлеге или дать еду за пределами юрты. Только те, кто имел семью, имели авторитет и влияние в обществе, что сохраняется у монгольских тувинцев по сей день [Айыжы 2017: 62-63].

Такое явление, как «старая дева», было характерно и для культур народов Саяно-Алтайского нагорья. Отношение традиционного общества к женщинам дулгуяк было противоречивым. С одной стороны, они могли быть шаманками и знахарками, а с другой - им приписывалась способность преднамеренного вредительства, и потому они не могли быть повитухами, присутствовать при родах, участвовать в свадебных обрядах. Необходимо подчеркнуть, что в экономическом, социальном и правовом отношении были ущемлены не только женщины, не состоящие в браке, но и мужчины. Состояние холостяка приравнивалось к без- нравственному поведению. Женщина без мужа не имела самостоятельной ценности, статус женщины дулгуяк в традиционном обществе тувинцев воспринимался как социально неполноценный.

Обязательным был брак и у южных алтайцев. Практически бесправным было положение в обществе тех, кто не состоял в браке. Старые девы и холостяки не имели даже своего айила, лишь женатые (кижилу) и замужние (кижиде) имели авторитет и влияние в обществе [Тадина 1992: 57].

В традиционной тувинской культуре «старые девы» были явлением крайне редким, что было связано с традиционным воззрением тувинцев о главном предназначении женщины быть женой и матерью. Женщина-тувинка, будучи многодетной матерью, повседневно выполняла большой круг трудоемких и тяжелых обязанностей по дому и хозяйству, что было не так просто. При этом она была во многом равной мужчине, так как, выходя замуж « ... принесла во вновь организовавшееся хозяйство и юрту, и весь хозяйственный обиход, и часть скота» [Яковлев 2007: 240]. «Собственность тувинской невесты, жены была неотчуждаемой, так как она готовилась, собиралась ее родителями и родственниками. Именно это имущество делало невесту независимой и экономически, и морально в семье, в кругу родственников мужа» [Биче-оол 2018: 79-80].

По религиозным представлениям тувинцев, женщина, которая не замужем и не имеет детей, после смерти превращается в злого духа и приносит людям разные беды. Поэтому таких женщин остерегались, старались с ними не общаться [Катанов 2011: 80].

То, что дулгуяк-кадай в традиционном тувинском обществе было редким явлением, предопределялось кочевым образом жизни в суровых природно-климатических условиях: в жены брали не только для продолжения рода и воспитания детей, но и для ведения домашнего хозяйства. В натуральном хозяйстве тувинцев, основанном на пастбищном скотоводстве и промысловой охоте в сочетании с земледелием, где все необходимое для жизни изготовляли домашним способом, труд женщины, как и мужчины, был одинаково важным [Доржу 2011: 35]. 
Свою роль играл и калым: выдавая дочь замуж, родители могли получить за нее скот или другое имущество.

Итак, статус дулгуяк-кадай в семье был крайне низким, поэтому девушки старались обязательно выйти замуж. Считалось позором, если уже взрослая, но незамужняя дочь оставалась жить в родительском доме. Ее положение в семье во многом зависело от отношения к ней отца или брата, если он был главой семьи.

В дореволюционной Туве тувинцы жили аальной общиной, состоявшей из двух-трех поколений родственников. Общению молодежи, установлению брачно-семейных отношений во многом способствовали ночные молодежные игрища - ойтулааш. По сообщению нашего респондента, 80-летней В. Б. Монгуш, ойтулааш устраивались с начала лета и до окончания осени, с позднего вечера до рассвета, вдали от жилища, куда можно было добраться только верхом на лошадях. На игрищах парни и девушки знакомились. Игрища позволяли молодежи лучше узнать своих родственников из других районов, дабы не нарушить вековые обычаи, запрещавшие создавать семьи детям близких родственников [ПМА: Монгуш 2019].

Постепенно засидевшиеся невесты меняли повседневную одежду на более «смиренную» - тон темного цвета без украшений, скромный головной убор, одна коса. Носить такую одежду было обязательным, а в старости дулгуяк-кадай свои украшения: серьги, перстни, браслеты, гребни раздаривали молодым родственницам.

Итак, исследования показали, у разных народов к старым девам относились примерно одинаково: они вызывали недоверие, жалость и даже откровенное презрение. Так, у хакасов, если по достижении брачного возраста (17-22 года) девушка не была замужем, ее называли чурт айна ('домашний черт') [Кустова 2000: 79-80].

Исследования показали, что возраст старых женщин зависит от традиций того или иного народа и времени, о котором идет речь. Это связано скорее с промежуточным состоянием, когда «старая дева - ни с бабами, ни с девками», то есть «уже не... и еще не...». Так, например, «нормальным» брачным возрастом у тувинских женщин считалось 16-20 лет, что значительно ниже, чем в настоящее время. Что касается современного тувинского общества, то «брачность» населения республики изменяется неоднозначно. Как в 80-90-х гг. прошлого, так и в начале нынешнего века, средний возраст девушек, вступающих в брак, одинаков - 20-21 лет. Однако если в прошлом традиционно в брак вступали в более раннем возрасте, то в современных условиях, с возможностью и желанием молодежи получить образование, сделать карьеру и т. д., возраст заключающих брак увеличился.

Отметим, что в традиционном тувинском обществе негативным было отношение не только к старым девам, но и к мужчинам, не имеющим семью. Это подтверждают и наши респонденты, приводя многочисленные примеры из личного опыта. Однако, как утверждает В. Б. Монгуш, отношение к холостякам было более лояльным, нежели к дулгуяк-кадай [ПМА: Монгуш 2019]. Наш другой информатор, М. Д. Шойдак, объясняет это тем, что брачный возраст женщины более подвижный, что связано, скорее всего, с ее способностью рожать детей, быть матерью, учитывая ценность брака в традициях тувинцев [ПМА: Шойдак 2019].

Как свидетельствуют информанты, никто не хотел жениться на старой деве. Если все-таки это происходило и юноша женился на старой деве, что, впрочем, было весьма редким явлением, это считалось большим позором и для молодого человека, и для его семьи. В то время как засидевшейся невесте ничего не оставалось, как выйти замуж либо за вдовца, либо найти жениха, отвергнутого другими девушками из-за бедности, физических недостатков или крайней безнравственности.

\section{Дулгуяк-кадай в современном тувин-}

\section{ском обществе}

В современном тувинском обществе меняется как возраст вступающих в брак, так и модель традиционного брака. В Туве все большее распространение получает сожительство мужчин и женщин вне регистрации, то есть так называемый гражданский брак. Растет и число внебрачных детей. Так, только в 2006 г. в целом по республике число таких детей составило 67,8 \%, в городах - 63,8 \%, в сельских поселениях - 71,2 \% [Доржу 2018: 2]. Больше всего материнская семья распространена среди 15-19-летних и женщин после 35 лет. В 
первом случае, как утверждают наши респонденты, это можно объяснить тем, что на селе многие семьи утратили постоянные источники доходов, выросла безработица, и пособие на детей для них является одним из основных доходов. Во втором случае, как показали наши исследования, сказывается экономическая самостоятельность и высокий образовательный уровень городских женщин, пожелавших родить для себя. И в том, и в другом случае женщины, родившие ребенка вне брака, не вызывают осуждение или жалость со стороны своих семей и общества, к ним относятся как к женщине-матери. Все это говорит о том, что традиционный брак как единственная форма совместной жизни тувинцев, уходит в прошлое [Доржу 2019: 8].

\section{Результаты}

Исследование показало, что в современном тувинском обществе коренным образом изменилось отношение к тем, кто по той или иной причине не состоит в браке. Если в традиционном обществе созданию семьи придавалось особое значение и всякий, не вступивший в брак, особенно дулгу-

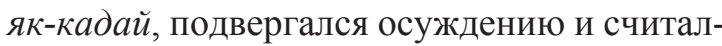
ся ущербным, то в настоящее время такое не наблюдается. Согласно переписи населения, в 2019 г. общая численность жителей Тувы составляет 324423 человека, из них 155363 мужчины и 169060 женщин, что подтверждает наличие демографического дисбаланса [Численность населения 2019]. Наблюдается некоторая, а местами значительная, диспропорция бракоспособного контингента из-за того, что мужчин меньше, чем женщин, поэтому всё чаще встречаются одинокие женщины.

В подавляющей части современного общества сформировалось мнение, что старая дева, в отличие от традиционных представлений, - это девушка старше 22 лет (если учесть средний возраст мам), физически и морально здоровая, но не имевшая сексуального опыта. Все чаще в числе старых дев оказывается вполне обеспеченная и самостоятельная девушка, но с завышенными требованиями к окружающим.

Опыт исследования показывает, что положение дулгуяк-кадай как в традиционной культуре тувинцев, так и в современном обществе - это проблема места и роли такой социально-демографической группы, как одинокие женщины в социальной структуре общества, их социального статуса и еe составляющих. Образ жизни одиноких женщин, отношение семьи и общества к ним предопределяются постоянно изменяющимися историческими и социально-экономическими условиями, а в современных условиях существующее напряжение может быть снято за счет адекватного повышения качества жизни в материальной и политической сферах жизнедеятельности современного общества.

\section{Полевые материалы авторов}

ПМА: Суван 2018 - Беседа с Январь Демировной Суван, 1941 г. р., пенсионер. Работала учителем тувинского языка и литературы в Чаа-Хольской средней школе Улуг-Хемского кожууна. Запись в г. Кызыле 27.07.2018.

ПМА: Шойдак 2019 - Беседа с Маргаритой Дугаржаповной Шойдак, 1947 г. р., пенсионер. Работала учителем начальных классов с. Хандагайты Овюрского кожууна. Запись в п. Межегей Тандинского кожууна 17.06.2019, 18.06.2019.

ПМА: Монгуш 2019 - Беседа с Валентиной Бегзиевной Монгуш, 1940 г. р., пенсионер. Работала учителем тувинского языка и литературы в с. Кызыл-Мажалык Барун-Хемчикского кожууна. Запись в г. Кызыле 26.07.2019, 28.07.2019.

\section{Литература}

Айыжы 2017 - Айыжы E. В. Формы семьи и брака тувинцев России, Монголии и Китая // Вестник Калмыцкого института гуманитарных исследований РАН. 2017. С. 58-66.

Биче-оол 2018 - Биче-оол С. М. Традиционные брачно-семейные отношения у тувинцев и их трансформация в советский период. Абакан: Журналист, 2018. 128 с.

Доржу 2011 - Доржу 3. Ю. Тувинская семья: тенденции ее жизнедеятельности // Омский научный вестник. Серия «Общество. История. Современность». 2011. № 1. С. 35-38.

Доржу 2018 - Доржу 3. Ю. Из истории женского движения в Туве // IV Центральноазиатские исторические чтения. Пространство культур: через призму единства и многообразия. Сб. мат-лов междунар. науч.-практ. 
конф. Кызыл: Тувинск. гос. ун-т, 2018. C. 198-205.

Доржу 2019 - Доржу 3. Ю. Межэтническое взаимодействие русских и тувинцев в советской и постсоветской Туве (на примере национально-смешанных семей) // Новые исследования Тувы. 2019. № 1. С. 144-156.

Забелина 2010 - Забелина Г. А. Женщины Тувы в семье и обществе в первой половине ХХ века. Кызыл: ТувИКОПР СО РАН. 2010. $118 \mathrm{c}$.

Катанов 2011 - Катанов Н. Ф. Очерки Урянхайской земли (Дневник путешествия, исполненного в 1889 году по поручению Императорской Академии наук и Императорского Русского географического общества). Антропология, этнография, мифология, фольклор. Абакан: Журналист, 2011. $84 \mathrm{c}$.

Кенин-Лопсан 2006 - Кенин-Лопсан М. Б. Традиционная культура тувинцев. Кызыл: Тув. кн. изд-во, 2006. 232 с.

Кон $2007-$ Кон Ф. Я. Экспедиция в Сойотию // Урянхай: Тыва дептер / сост. С. К. Шойгу. Т. 4. М.: Слово, 2007. С. 348-548.

Курбатский $2001-$ Курбатский Г. Н. Тувинцы в своем фольклоре (историко-этнографиче-

\section{Authors' Field Data}

Informant: Yanvar D. Suvan, b. 1941, a retired school teacher (Tuvan language and literature; Chaa-Khol village, Ulug-Khemsky District, Tyva Republic). Rec. in Kyzyl on July 27, 2018. (In Tuv. and Russ.)

Informant: Margarita D. Shoydak, b. 1947, a retired school teacher (primary grades; Khandagayty village, Ovyursky District, Tyva Republic). Rec. in Mezhegei village (Tandinsky District) on June 17-18, 2019. (In Tuv. and Russ.)

Informant: Valentina B. Mongush, b. 1940, a retired school teacher (Tuvan language and literature; Kyzyl-Mazhalyk village, Barun-Khemchiksky District, Tyva Republic).Rec. in Kyzyl on July 26-28, 2019. (In Tuv. and Russ.)

\section{References}

Aiyzhy E. V. Tuvans of Russia, Mongolia and China: forms of family and marriage. Bulletin of the Kalmyk Institute for Humanities of the RAS (Oriental Studies). 2017. Vol. 29. No. 1. Pp. 58-66. (In Russ.) DOI: 10.22162/20757794-2017-29-1-58-66

Biche-ool S. M. [Tuvan Traditional FamilyMarriage Relations and Their Transformation ские аспекты тувинского фольклора. Кызыл: Тув. кн. изд-во, 2001. 462 с.

Кустова 2000 - Кустова Ю. Г. Ребенок и детство в традиционной культуре хакасов. СПб.: Петербургское востоковедение, 2000. 160 с.

Менхен-Хельфен 2007 - Менхен-Хельфен $O$. Путешествие в азиатскую Туву // Урянхай: Тыва дептер / сост. С. К. Шойгу. Т. 6. М.: Слово, 2007. С. 220-352.

Тадина 1992 - Тадина Н. А. Формы заключения брака и ритуальное поведение у алтайцев. Этнографическое обозрение. 1992. № 4. С. $50-57$.

Численность населения 2019 - Численность населения за 2019 год [электронный ресурс] // Статистика по России. Республика Тува: общая демография. URL: https://russia.duck. consulting/regions/17 (дата обращения: 15.12. 2019).

Юша 2018 - Юша Ж. М. Фольклор и обряд тувинцев Китая в начале XXI века. Структура. Семантика. Прагматика. Новосибирск: Наука, СО РАН. 2018. 400 с.

Яковлев 2007 - Яковлев Е. К. Этнографический обзор инородческого населения долины Южного Енисея // Урянхай: Тыва дептер / сост. С. К. Шойгу. Т. 5. М.: Слово, 2007. C. 202-253.

during the Soviet Era]. Abakan: Zhurnalist, 2018. 128 p. (In Russ.)

Dorzhu Z. Yu. Interethnic interaction of Russians and Tuvans in Soviet and post-Soviet Tuva: the case of ethnically mixed families. The New Research of Tuva. 2019. No. 1. Pp. 144-156. (In Russ.)

Dorzhu Z. Yu. Tuvan family: functioning trends. Omsk Scientific Bulletin. Series Society. History. Modernity. 2011. No. 1. Pp. 35-38. (In Russ.)

Dorzhu Z. Yu. Women's movement in Tuva: glimpses of history. In: $\left[4^{\text {th }}\right.$ Central Asian Historical Readings. Space of Cultures: through the Prism of Unity and Diversity]. Conf. proc. Kyzyl: Tuvan State University, 2018. Pp. 198205. (In Russ.)

Katanov N. F. [Essays on the Land of Uryankhai: Notes on the 1889 Journey Sanctioned by the Imperial Academy of Sciences and Imperial Russian Geographic Society. Anthropology, Ethnography, Mythology, Folklore]. Abakan: Zhurnalist, 2011. 84 p. (In Russ.)

Kenin-Lopsan M. B. [Tuvan Traditional Culture]. Kyzyl: Tuvan Book Publ., 2006. 232 p. (In Russ.) 
Kon F. Ya. Expedition to Soyotia. In: [Uryankhai: Tyva Depter]. S. K. Shoygu (comp.). Moscow: Slovo. Vol. 4. 2007. Pp. 348-548. (In Russ.)

Kurbatsky G. N. [Tuvans in Their Folklore: Historical and Ethnographic Aspects of Tuvan Folklore]. Russian Academy of Sciences, Siberian Branch, Institute of Archaeology and Ethnography. Kyzyl: Tuvan Book Publ., 2001. 462 p. (In Russ.)

Kustova Yu. G. [Child and Childhood in Khakas Traditional Culture]. St. Petersburg: Peterburgskoe Vostokovedenie, 2000. 160 p. (In Russ.)

Mänchen-Helfen O. Journey to Tuva. In: [Uryankhai: Tyva Depter]. S. K. Shoygu (comp.). Moscow: Slovo, 2007. Vol. 6. Pp. 220-352. (In Russ.)

Russia in Numbers. Population Size: 2019 (Republic of Tuva). Available at: https://russia.duck. consulting/regions/17 (accessed: December 15, 2019). (In Russ.)

Tadina N. A. [The Altaians: Consummation of Marriage and Ritual Behavior]. Etnograficheskoe Obozrenie. 1992. No. 4. Pp. 50-57. (In Russ.)

Yakovlev E. K. Non-Russian Population of the Southern Yenisei Valley: Ethnographic Review. In: [Uryankhai: Tyva Depter]. S. K. Shoygu (comp.). Moscow: Slovo, 2007. Vol. 5. Pp. 202-253. (In Russ.)

Yusha Zh. M. [Folklore and Ritual of ChinaBased Tuvans, Early $21^{\text {st }}$ Century: Structure, Semantics, Pragmatics]. Sib. Branch of RAS. Novosibirsk: Nauka, 2018. 400 p. (In Russ.)

Zabelina G. A. [Women of Tuva in Family and Society: Early to Mid-20 $0^{\text {th }}$ Century]. Kyzyl: Tuva Institute for Exploration of Natural Resources (Sib. Branch) of RAS, 2010. 118 p. (In Russ.). 